\title{
O ESCOPO DA AVALIAÇÃO COLABORATIVA
}

\section{THE SCOPE OF COLLABORATIVE EVALUATION}

\author{
Jairit Garavit ${ }^{2}$ \\ https://orcid.org/0000-0003-1976-9891
}

1. ¿Este produto é o resultado do trabalho árduo de uma de suas Linhas de Pesquisa do projeto "Como deve pesquisar em Educação virtual e a distância?" do ano de 2021, realizada com Membros de forma interdisciplinar e interinstitucional (Professores - Alunos) da Pesquisa Seedbed: Sistemas Integrados de Gestão "Integradoss" Anexados ao GrupLAC: SIGCIENTY da Universidade Nacional Aberta e a Distância UNAD.

2. Engenheiro Industrial, Especialista em Educação Superior e à Distância, Mestre em Sistemas Integrados de Gestão HSEQ-RSC, Revisor de Pares da Elsevier, Revisor de Pares da Publons Academy e Advisor \& Peer Rewiever de Mendeley, Editor de Currículo em Revistas Acadêmicas - Minciencias. Líder da Seedbed de Pesquisa "Integradoss" e nomeado Professor Pesquisador da Escola de Ciências Básicas, Tecnologias e Engenharia ECBTI. Zona Caribenha, na Universidade Nacional Aberta e a Distância - UNAD. Email institucional Jairit.Garavit@unad.edu.co

Projeto de Pesquisa: ¿Cómo pesquisar em Educação virtual e a distância? 
Resumo: O curso da avaliação começa com a caracterização das principais pistas mutuamente estabelecidas. A avaliação é bem-sucedida ao consumir um projeto, uma investigação ou em períodos explícitos durante a execução. Da mesma forma, pode ser o avanço em uma tática de estimativa que apóia a invenção e o aumento incessante no fornecimento de feedback em períodos de tempo real em ambientes atenciosos e acadêmicos. O objetivo é visualizar rapidamente a modelagem dos cursos de aprimoramento, fornecendo conhecimentos essenciais para fornecer ensino e comunicar decisões; O capítulo externaliza o que poderiam ser alguns dos auxílios de treinamento e uma avaliação colaborativa profundamente legal, tendo uma avaliação legítima no treinamento, origina verdadeiramente um ensino integral e colaborativo.Por isso, examine a ideologia e para uma estimativa da aprendizagem permissível a ser dada, suas derivações de aprendizagem devem compensar socialmente os alunos do século XXI. Esta redação instrui certos testes conceituais, usando representações de três estimativas colaborativas para o treinamento que estão sendo trabalhados atualmente.

Palavras chaves: Avaliação colaborativa, validade na avaliação, treinamento colaborativo, estratégias de aprendizagem.

Abstract: The course of the assessment begins with the characterization of key mutually established leads. The evaluation succeeds when consuming a project, an investigation or in explicit periods during the execution. Likewise, it may be the advance in an estimation tactic that supports invention and the incessant increase in providing feedback in real time periods in caring and academic environments. The objective is to quickly visualize the improvement courses modeling, providing key knowledge to provide instruction and communicate decisions; The chapter externalizes what could be some of the training aids and a deeply legal collaborative assessment, taking a legitimate evaluation in the training, truly originates a comprehensive and collaborative teaching Therefore, Examine the ideology and to give an estimate of permitted learning, its learning derivations should be socially rewarding for 21 st century learners. This writing instructs certain conceptual tests, using representations of three collaborative estimates for training that are currently being worked on.

Keywords: Collaborative evaluation, validity in evaluation, collaborative training, learning strategies.

\section{Introdução}

A validade dos testes é um tópico muito debatido, mas a validade das avaliações para a aprendizagem (ou avaliações formativas) é uma área de diálogo mais recente. O objetivo de um teste sumativo é resumir a aprendizagem, enquanto o objetivo de uma avaliação de aprendizagem é promover a aprendizagem: portanto, é importante distinguir entre o que 
caracteriza um teste sumativo altamente válido e o que caracteriza uma avaliação altamente válida para a aprendizagem. Este capítulo primeiro explora as características que contribuem para a validade da avaliação para a aprendizagem, particularmente aquelas do treinamento colaborativo para a aprendizagem, devido aos benefícios de aprendizagem associados ao treinamento colaborativo autônomo. Subseqüentemente, alguns dos benefícios de aprendizagem de uma avaliação colaborativa válida para treinamento são indicados, assumindo que uma avaliação altamente válida para aprendizagem realmente promove a aprendizagem (Black \& William, 1998; Stobart, 2006).

Ele explora a ideia de que uma avaliação será mais válida se seus resultados de aprendizagem forem socialmente apropriados para os alunos do século XXI. O artigo ilustra alguns desses pontos conceituais, usando descrições de três avaliações colaborativas de aprendizagem que estão sendo praticadas atualmente. Ele explora a ideia de que uma avaliação será mais válida se seus resultados de aprendizagem forem socialmente apropriados para os alunos do século XXI.

$\mathrm{O}$ artigo ilustra alguns desses pontos conceituais, usando descrições de três avaliações colaborativas de aprendizagem que estão sendo praticadas atualmente. Ele explora a ideia de

que uma avaliação será mais válida se seus resultados de aprendizagem forem socialmente apropriados para os alunos do século XXI. O artigo ilustra alguns desses pontos conceituais, usando descrições de três avaliações colaborativas de aprendizagem que estão sendo praticadas atualmente.

\section{Determinação do impacto}

As avaliações colaborativas do projeto que se concentram nos resultados das atividades do projeto demonstram responsabilidade; os resultados também podem ser usados para obter apoio para a sustentabilidade e financiamento do programa e demonstrar a eficácia da colaboração; As avaliações fornecem informações importantes que permitem que as partes interessadas, professores, alunos, colegas, parceiros e outros aprendam com os sucessos e desafios do trabalho conjunto. $\mathrm{O}$ acordo coletivo sobre como o sucesso ou eficácia da colaboração será medido garante que os alunos permaneçam alinhados com sua visão compartilhada e sejam responsabilizados pelos resultados do projeto.

Um processo de avaliação de desenvolvimento que fosse flexível o suficiente para se adaptar às circunstâncias do mundo real do projeto e às realidades concorrentes dos diferentes mandatos das organizações parceiras foi crucial. À medida que avançamos, fomos capazes de desenvolver nossos sucessos e aprender com os desafios.

Nossos programas acadêmicos de treinamento estão se movendo de maneira funcional? Esta é uma questão chave na educação hoje, particularmente nesta era de maior 
responsabilidade. Um modelo de avaliação de programa colaborativo é uma forma extremamente útil de responder a essa pergunta quando as organizações educacionais desejam saber se suas iniciativas estão alcançando os resultados esperados, e também por quê.

No modelo de avaliação de programa colaborativo, o cliente (por exemplo, distritos, estados, escolas públicas e independentes, organizações sem fins lucrativos e fundações) trabalha com o avaliador externo para determinar as questões a serem exploradas por meio da avaliação. Eles continuam a trabalhar colaborativamente para garantir que o contexto seja compreendido, as perspectivas de múltiplas partes interessadas sejam levadas em consideração e os instrumentos de coleta de dados sejam adequados em conteúdo e tom. $\mathrm{O}$ modelo produz dados que podem informar proativamente a implementação do programa, fornecer informações formativas que apóiam a melhoria do programa e fornecer informações resumidas sobre a eficácia do programa.

\section{Avaliações na aprendizagem}

A frase avaliação para aprendizagem (ou avaliação formativa) denota avaliação usada especificamente para melhorar os processos de aprendizagem ou desempenho, ao invés de apenas medi-los. Embora qualquer avaliação afete a aprendizagem do aluno de forma direta ou menos direta (Torrance \& Pryor, 1998), a ideia da avaliação para a aprendizagem é que a intenção primária e o resultado da avaliação é melhorar a aprendizagem. Uma ampla gama de práticas tem sido associada à realização de avaliações para a aprendizagem, como professores compartilhando fundamentos de avaliação com os alunos, professores incentivando os alunos a se autoavaliarem e professores e alunos focando em como aprendemos (Arg, 2002). Na Colômbia,

\section{Validade no contexto da avaliação colaborativa}

Em relação à avaliação somativa, um teste não é mais considerado como tendo validade como propriedade inerente (Messick, 1989). Em vez disso, sua validade consistente é enfatizada e uma avaliação tem alta validade se as consequências da interpretação e do uso do teste não apenas apoiarem os propósitos pretendidos, mas também forem consistentes com outros valores sociais (Gipps, 1994, p. 62) . Em termos de avaliação formativa, então, a

validade de uma avaliação para a aprendizagem depende de até que ponto a interpretação e o uso da avaliação realmente levam a uma aprendizagem posterior.

Isso significa que simplesmente projetar uma avaliação para promover a aprendizagem não a torna válida. Nessa visão, para ser altamente válida, uma avaliação também deve gerar um alto grau de aprendizagem desejada. Além disso, o aprendizado que se segue deve ser 
consistente com outros valores sociais. Quem decide quais são as prioridades sociais em determinado momento é, evidentemente, uma questão problemática, mas este capítulo tenta provocar reflexão sobre a questão.

Os comentários acima sugerem que a validade de uma avaliação para a aprendizagem requer que a aprendizagem realmente ocorra; mas esse resultado depende de como o avaliador define a aprendizagem, que por sua vez depende de valores sociais específicos. Portanto, teoricamente, se uma avaliação realmente promove a aprendizagem, mas essa aprendizagem não está de acordo com as prioridades sociais, a avaliação é inválida. Portanto, para julgar a validade de uma avaliação para o aprendizado, o avaliador (e o avaliado?) Precisa saber que o aprendizado que ele promove é valioso. Um diálogo sobre que tipo de aprendizagem valorizamos deve preceder nossa avaliação se uma avaliação de aprendizagem é válida ou não.

¿No entanto, como sabemos que qualquer aprendizado adicional, "processos ou resultados" resultou de uma avaliação? Muito do aprendizado valioso não é previsível nem observável, e todos nós estamos familiarizados com a experiência de dar significado muito depois de um evento. Um aluno responderá de forma diferente de outro: o que é significativo para um aluno pode passar despercebido. Perrenoud (1998) com sua pesquisa, lembrou-nos que, entre o que o aluno faz e o que lhe passa pela cabeça, as mediações são complexas.

E o que acontece na mente não afeta necessariamente o aprendizado. Portanto, em todos esses aspectos, às vezes podemos não saber qual aprendizado adicional resultou de nossas avaliações para o aprendizado e, nesse sentido, não podemos julgar completamente até que ponto a avaliação é válida. Mas essas não são boas razões para evitar a promoção de avaliações válidas de aprendizagem, usando as melhores evidências que podemos para proteger sua validade. Nas ilustrações abaixo, nenhuma tentativa é feita para quantificar ou mesmo provar que um aprendizado valioso está ocorrendo, e ainda assim as descrições ajudam a ilustrar o que podemos estar procurando em uma avaliação altamente válida para o aprendizado.

\section{Impacto e objetivo da avaliação na aprendizagem}

Stobart (2006) nos lembra que a validade na avaliação consiste fundamentalmente em fazer uma articulação adequada entre a avaliação e o construto que ela mostra. Isso, ele nos diz, é essencialmente sobre adequação a um propósito. Em termos de avaliação formativa ou avaliação da aprendizagem, onde a ênfase está nas consequências, a questão é se o formulário de avaliação promove o tipo de aprendizagem em que queremos que os nossos alunos participem. Diferentes formas de avaliação promovem diferentes formas de aprendizagem, seja a avaliação formativa ou sumativa. Se os alunos participam da aprendizagem 
colaborativa regularmente, mas a avaliação não é colaborativa, é improvável que a avaliação mostre seu construto de forma eficaz.

Além disso, a avaliação tem impacto na aprendizagem que ocorre em sala de aula. Se nossa avaliação é para aprendizagem, então há uma razão convincente para garantir que os efeitos colaterais de qualquer avaliação sejam positivos; ou seja, que sua forma e conteúdo promovem o conhecimento, as habilidades, a compreensão e as atitudes que são valorizadas (Frederickson \& Collins, 1989). No caso de treinamento colaborativo, a forma e o conteúdo da avaliação devem refletir e promover as técnicas e derivações do colaborativo.

Os próprios avisos de avaliação podem ser um estágio primordial para gerar aprendizado útil por meio da avaliação. Se as atividades de avaliação colaborativa levarem a processos de aprendizagem significativos durante as atividades de avaliação utilizadas, elas terão alguma validade como avaliações para a aprendizagem, independentemente de seus resultados de longo prazo. Nesse contexto, a aprendizagem adicional gerada pode assumir a forma de construção de conhecimento em uma experiência participativa, ao invés da forma de aquisição de habilidades específicas posteriormente.

Outras características relacionadas à validade da avaliação colaborativa para a aprendizagem. Portanto, estou argumentando que até que ponto uma avaliação colaborativa para a aprendizagem é válida depende de até que ponto ela realmente promove um aprendizado valioso. Crooks $(1996,2001)$ os trabalhos sobre a validade da avaliação formativa não se concentram na aprendizagem colaborativa; mas são úteis em sua sugestão de que a validade das avaliações formativas pode ser ameaçada se as condições de aprendizagem não forem favoráveis.

No caso da avaliação colaborativa, algumas condições essenciais que contribuem para a validade da avaliação para a aprendizagem incluem: foco na aprendizagem em sala de aula; a familiaridade de alunos e professores com situações de treinamento colaborativo; sua familiaridade com os objetivos e processos da avaliação; a adequação da tarefa de avaliação; e a importância do feedback construído. Em avaliações tradicionais, o feedback é frequentemente visto como o que o professor faz para guiar os alunos no caminho certo em sua jornada de aprendizagem (Black \& William, 1998).

Em uma situação colaborativa, é mais provável que o feedback seja na forma de desafios apresentados por colegas, atividade de autorregulação do próprio aluno ou ajuda produtiva entre os membros do grupo.

Serafini (2001) equiparou a palavra avaliação com medição, procedimento ou investigação. É improvável que uma avaliação colaborativa para treinamento tome a forma de uma medição que resulte em classificação ou classificação (embora possa incluir alguns 
itens de medição ou ser acompanhada por medições). Isso porque a mensuração depende de uma visão do conhecimento em que se acredita que o conhecimento existe separadamente do aluno, e os alunos trabalham para adquiri-lo, não para construí-lo (Serafini, 2001).

Essa visão de conhecimento é contrária a uma visão colaborativa em que alunos e professores participam de um diálogo de construção de conhecimento. Uma avaliação colaborativa para a aprendizagem tende a ser uma investigação, em que o conhecimento é considerado construído pelo indivíduo dentro dos contextos sociais do evento de aprendizagem e múltiplas interpretações são encorajadas, com cada aluno transacionando com diferentes textos e o mundo para criar significados ( Rosenblatt, 1979) (Serafini, 2001).

\section{O valor da aprendizagem embutida na colaboração}

Argumentei anteriormente que uma avaliação válida para o aprendizado promove um aprendizado valioso. Sugeri que a validade tende a ser maior quando a forma da avaliação é adequada para o propósito e quando as condições são apropriadas. Sugeri que o aprendizado valioso pode estar associado ao conhecimento socialmente construído; e que o conhecimento socialmente construído é uma característica da aprendizagem e avaliação colaborativas. Na próxima seção, examinamos os processos pelos quais o conhecimento pode ser socialmente construído na sala de aula; e por que esse aprendizado pode ser considerado "válido".

\section{Os termos do treinamento colaborativo}

O conhecimento pode ser construído socialmente por meio de processos de treinamento colaborativos. Esta formação é um estágio em que todos têm um papel mais ou menos igual na construção dos saberes designados. Todos os membros do grupo, seja um grupo de classe completa ou um pequeno grupo, têm o mesmo valor, embora suas contribuições sejam diversas. Os alunos colaborativos complementam e se baseiam nas perspectivas de outros, para construir um conhecimento compartilhado. Por exemplo, se cada um dos membros de um grupo leu um texto diferente relacionado a um tópico (por exemplo, o tópico: treinamento colaborativo), compartilhando os significados que cada um fez de um texto diferente, como grupo eles constroem um rico imagem (de formação colaborativa). Este é um conhecimento construído socialmente,

Os alunos colaborativos tendem a expressar ideias emergentes ou intuitivas e, portanto, têm a oportunidade de testá-las em público (Crook, 1994). Quando há uma discordância, isso

incentiva a reflexão e a exploração crítica de uma questão dentro do grupo; e ao mesmo tempo ajuda cada um a reafirmar a sua posição. Portanto, o treinamento colaborativo é caracterizado de forma semelhante a Watkins (2004) pela interação da reflexão privada e pública. Quando um grupo colabora com sucesso, o agente de pesquisa não é o indivíduo, 
mas o grupo de construção do conhecimento: os alunos assumem a responsabilidade de saber o que precisa ser conhecido e garantir que os outros saibam o que precisa ser conhecido.

Outros termos para este processo de construção de conhecimento social incluem "treinamento de pares" (Boud et al., 1999). O treinamento colaborativo não deve ser confundido com o ensino por pares, no qual um aluno assume o papel de professor em relação a outro aluno. E a aprendizagem colaborativa não acontece simplesmente colocando os alunos em pequenos grupos. Embora o professor tenha um papel menos intrusivo na formação dos alunos, sua importância na orientação da formação colaborativa não é menor do que na direção das salas de aula tradicionais. O desafio do professor é incentivar os alunos a colaborar, em vez de competir ou trabalhar juntos. Isso não acontecerá em um piscar de olhos e pode ser uma palestra muito desafiadora.

\section{Resultados de aprendizagem incorporados ao treinamento colaborativo}

O conhecimento construído por meio do treinamento colaborativo pode ser amplo, mas certos resultados de aprendizagem estão particularmente associados à aprendizagem colaborativa (e sua avaliação). Boudet al. (1999) observaram que as estratégias de treinamento colaborativo são tão bem-sucedidas na melhoria do conhecimento do assunto que as estratégias são freqüentemente empregadas mesmo quando a agenda de longo prazo é sobre realizações individualistas, ao invés de cultivar habilidades e perspectivas colaborativas. Além disso, o treinamento colaborativo pode produzir ganhos de aprendizagem impressionantes sem funcionários adicionais na sala de aula.

De fato, como Brown e Campione (1994) mostraram, os alunos colaborativos parecem reter melhor o assunto, fazer uso mais flexível da informação e aplicá-la de forma mais ampla. Portanto, os alunos colaborativos são mais propensos a ter sucesso, mesmo em versões tradicionais de aprendizagem. No entanto, os alunos colaborativos também mostram uma atitude mais positiva em relação ao seu tema e o abordam de forma mais ativa, envolvente, exploratória e profunda, além de estarem mais conscientes de como aprendem: tudo isso também leva a um aluno melhor como aqueles que obtêm melhores resultados em exames formais (Watkins et al., 2001).

As relações aluno-professor melhoram com o uso de treinamento colaborativo e, à medida que o fazem, A motivação e os sentimentos de autonomia e competência dos alunos aumentam, o que, por sua vez, também conduz a processos de aprendizagem adicionais (Battistichet al., 1995). Uma avaliação colaborativa baseada em um mesmo treinamento pode contribuir para a disposição do aluno em continuar aprendendo e aprimorar suas estratégias para tanto. 
Seja qual for o tópico que está sendo estudado, o treinamento colaborativo desenvolve nas habilidades de pensamento dos alunos de níveis superiores, incluindo a capacidade de refletir e pensar criticamente. Se a aprendizagem é definida como a criação de significado em vez da aquisição de informações, a reflexão e o pensamento crítico são ferramentas importantes, especialmente nesta era em que as informações são facilmente acessadas, mas menos significativas.

Outras habilidades promovidas pelo treinamento colaborativo incluem habilidades de comunicação oral, habilidades de argumentação, empatia, experiências de intervenção social e habilidades de liderança. Os relacionamentos dos alunos melhoram à medida que eles se responsabilizam mutuamente de forma colaborativa, superando diferenças raciais e outras. Aprender pode ser visto, neste contexto, como o conhecimento de participar e contribuir socialmente.

Embora todos os itens acima possam não ser objetivos de aprendizagem tradicionais, sua utilidade como resultados de aprendizagem é sublinhada hoje com uma nova ênfase em atributos ou capacidades genéricas, devido às situações cada vez mais complexas que as pessoas enfrentam dentro e fora do local de trabalho e, portanto, , a necessidade de adotar; aprendizagem ao longo da vida (Boud et al., 1999). Na verdade, alguns argumentam que toda aprendizagem humana é necessária e fundamentalmente social (Watkins, 2005).

Quando falamos em avaliação para a aprendizagem promovendo a aprendizagem, embora possamos significar retenção e utilização de informações ou competências específicas da disciplina (avaliadas através de provas escritas), pode ser meritória uma noção adicional, a de construção de sentido e de conhecimento participativo e social e contribuição da aprendizagem em diversos contextos.

É esse tipo de aprendizado que consideramos valioso? Se assim for, qualquer avaliação que realmente promova a construção de significados e conhecimentos de participação e contribuição social e de aprendizagem em diversos contextos tem alguma validade como uma avaliação para a aprendizagem. Se considerarmos que apenas resultados mensuráveis individualmente são aprendizagem meritória, então qualquer avaliação de aprendizagem que os promova é altamente válida.

Durante uma sessão de ensino universitário sobre avaliação de aprendizagem, perguntamos a um grupo de 21 professores e examinadores o que eles gostariam que os alunos aprendessem como resultado de sua escolaridade, e suas respostas incluíram o seguinte. Eles queriam que os alunos aprendessem a ser: empáticos, autoconscientes, socialmente competentes, resilientes, criativos, confiantes, responsáveis, atenciosos, autoavaliados, críticos, curiosos, aprendizes ao longo da vida, entusiastas da aprendizagem, 
bons cidadãos, independentes, dependentes, alegres, curioso, inventivo, animado, arriscado, tolerante, gentil, respeitoso, solidário, bom jogador de equipe, astuto, espontâneo, bem qualificado, fisicamente ativo e saudável. Eles queriam que os alunos tivessem as habilidades para: aplicar o conhecimento, aprender a aprender, resolução de problemas, autogestão, comunicação fluente e julgamentos morais sólidos. Por último, queriam que os alunos soubessem como dar uma contribuição social positiva.

Embora essa pesquisa supostamente tenha levado à cadeira de mestrado, não era um módulo de ensino particularmente relacionado à aprendizagem colaborativa. E, no entanto, muitas das habilidades mencionadas pelos participantes como resultados de aprendizagem meritórios são aquelas que são particularmente promovidas por meio do treinamento colaborativo e sua avaliação para a aprendizagem (talvez não as consequências da ação de saúde física! Astúcia através do treinamento colaborativo pode ser um pouco ambicioso!) Resumindo, estou sugerindo que uma versão valiosa de treinamento é criar significado e construir o conhecimento de participação e contribuição social e aprendizagem em vários contextos.

Proponho que esta versão de aprendizagem seja apoiada pela necessidade social atual de pessoas que são confiantes, autodirigidas e aprendizes contínuos, que têm uma consciência sensível dos outros, podem interagir bem com os outros e ser flexíveis na aplicação de informações. Eu me pergunto se uma versão de aprendizagem como a aquisição e uso de informações e habilidades ainda tem a moeda social que tinha antes da revolução da informação na qual a informação está prontamente disponível, mas sua aplicação inteligente ainda depende de decisões tomadas por seres sociais .

\section{Representações de avaliações colaborativas para a aprendizagem na prática, formando pontos sobre a validade da avaliação colaborativa para a aprendizagem em uma escola primária de Valledupar (Colômbia).}

Orlys Katrina leciona na turma de 6 (10-11 anos) da escola primária Gimnasio Infantil Valledupar, localizada em Valledupar - Cesar, Colômbia. Em colaboração com outros dois colegas, Orlys Katrina desenvolveu uma forma de avaliação colaborativa para ajudar seus alunos a aprender profundamente sobre conceitos específicos e também para ajudá-los a se tornarem alunos confiantes, aprender a se comunicar e aprender a cooperar.

Orlys Katrina, usou seu design de avaliação para aprender em seu ensino de dados discretos e contínuos e como os dados devem ser representados. Quando você começou, seus alunos já estavam familiarizados com o treinamento colaborativo. Desta vez, as crianças passaram um tempo em grupos de três para debater quais informações precisamos para um gráfico ser útil? Em seguida, Orlys Katrina compilou uma lista de flip chart no plenário com 
as sugestões de seus alunos. Quando toda a turma ficou satisfeita com a lista de critérios para o que torna um gráfico útil, cada criança individualmente criou uma história sobre o que um determinado gráfico significava, certificando-se de incluir em seu próprio gráfico todas as informações mencionadas como necessárias na lista da classe.

Tendo trabalhado sozinho nesta tarefa, o grupo de três se reuniu novamente para pensar novamente sobre qualquer informação que deveria ter sido incluída na lista da classe. Quando todos os membros do grupo concordaram, as novas sugestões foram enviadas para inclusão na lista revisada da turma. Depois de muita discussão, sua lista final é simplesmente:

- Um título completo ('Um gráfico mostrando a distância percorrida por ... durante ... etc.')

- Eixos etiquetados (com unidades claramente indicadas e escala demarcada).

Agora os alunos se mudaram para novos grupos de três. Cada um dos três alunos em um grupo compartilhou com as outras duas crianças seu próprio gráfico e a história que haviam criado em torno deles (no grupo anterior). Quando todos os três fizeram isso, o grupo teve que dividir 60 pontos entre os três, para refletir o quão bem cada criança havia levado em consideração as informações necessárias, em seu gráfico. Embora esse processo pareça anticolaborativo, Orlys Katrina relatou que a atividade gerou um diálogo muito rico sobre as características mais importantes do gráfico e exigiu um alto grau de cooperação e comunicação entre os membros do grupo enquanto eles comentavam suas razões uns com os outros. A professora, Orlys Katrina, nunca soube como eles atribuíram as notas, ou quais eram suas histórias.

Por fim, Orlys Katrina facilitou uma investigação em toda a turma das conclusões dos alunos sobre a representação dos dados em gráficos e também sobre como eles vivenciaram o aprendizado em grupo. Seus comentários sugeriram que, pelo menos para algumas crianças, a avaliação levou a um maior aprendizado da matemática, incluindo a compreensão de informações matemáticas. Por exemplo, o alunol escreveu: Descobri que assim que escolhi a escala para meus eixos, a história começou a se contar. Aluno2 disse a Orlys Katrina: Não sabia que a mesma linha poderia contar muitas histórias diferentes. No entanto, o aluno3 comentou que: Saber o que é uma boa história me ajudou a acertar minhas ideias. E o aluno 4 disse:

\section{Discussão sobre validade}

Em termos das ideias anteriores relacionadas à validade, pelo que podemos deduzir da observação das crianças, essa avaliação parece ter tido um alto grau de validade em termos de sua adequação ao propósito. A forma colaborativa da tarefa real e o papel do professor 
como guia, não como avaliador, eram consistentes com a visão valorizada de aprendizagem do professor como: desenvolvimento de habilidades matemáticas; construir conhecimento de participação e contribuição social; e aprenda sobre aprendizagem. Além disso, as condições de aprendizagem eram favoráveis, uma vez que as crianças estavam acostumadas ao treinamento colaborativo e ao diálogo. Embora neste projeto de avaliação de aprendizagem, os alunos realmente mediram suas realizações e as dos outros,

\section{Troca de informações úteis}

O início de uma forma inovadora e colaborativa de avaliação da aprendizagem, os professores e alunos das séries do ensino fundamental de Valledupar concentram suas energias no sucesso no exame final do ensino fundamental, o $5^{\circ}$ teste do sabre. No entanto, pais, educadores e empregadores reconhecem que a visão de túnel educacional que resulta de um foco no teste pode negar aos alunos as experiências de aprendizagem completas que os preparam para serem indivíduos socialmente responsáveis ou funcionários flexíveis e adaptáveis.

É por isso que o Ministério da Educação embarcou em um trabalho ambicioso no qual o treinamento colaborativo e a avaliação colaborativa para a aprendizagem desempenham um papel importante. O objetivo deste empreendimento é promover a área temática da cidadania, e promover a consciência-aprendizagem e a responsabilidade pela aprendizagem nos alunos, bem como a consciência social e a responsabilidade social.

Os promotores do programa concordam que, se os resultados de aprendizagem que esperam incluir treinamento em aprendizagem e aprendizagem social, para aumentar sua validade, as avaliações de aprendizagem devem incluir aspectos de colaboração. A fim de elevar o perfil dessa aprendizagem e avaliação não focadas em exames, o Departamento buscou financiamento da UNESCO.

O programa cobre dois períodos escolares. Para participar do projeto, todas as crianças do primeiro ano do ensino fundamental (10-12 anos) participam de aulas de aprendizagem sobre cidadania responsável. Depois de algumas dessas sessões, eles decidem sobre um projeto que gostariam de realizar dentro da comunidade (fora da escola) para melhorar um aspecto da comunidade e, assim, beneficiar a comunidade em geral e eles próprios. Ao fazer isso, eles trabalham de forma colaborativa como uma turma inteira (com um número de até 25 alunos).

Intermitentemente, em sala de aula, seu professor orquestra um processo de avaliação colaborativa para a aprendizagem em que todo o grupo se concentra em aprender sobre a aprendizagem, fazendo as seguintes indagações: Todos estão fazendo o dever de casa? Trabalhamos em equipe? Como podemos ajudar uns aos outros? Estamos felizes com o quê? 
O que não gostamos? Que mudanças podemos fazer na maneira como trabalhamos? (Jacobsen al., 2005). Os alunos fornecem feedback a si próprios e uns aos outros sobre os processos à medida que se autorregulam de forma colaborativa.

A próxima etapa do programa é que os alunos realizem o projeto que desenharam na comunidade. Por exemplo, um grupo de alunos decidiu fazer um mural para valorizar o ambiente e mostrar imagens importantes. Outro grupo iniciou um projeto com pessoas presas. Um terceiro e um quarto grupos começaram a trabalhar com pessoas viciadas em álcool e viciadas em drogas, respectivamente; Funcionários comunitários do Departamento de Assuntos Comunitários designados pelo Ministério da Educação (MEN) apoiam grupos de classe com seus projetos. As crianças são incentivadas a se envolver com pessoas da comunidade local em suas atividades, para que a comunidade possa aprender com elas e ajudá-las.

No final do projeto (por exemplo, quando o mural é concluído), as crianças escrevem e enviam um relatório do projeto compilado de forma colaborativa, como um produto do programa. Ao compilar isso, eles autoavaliam seus processos de aprendizagem e resultados. O outro produto é uma avaliação na forma de apresentação do projeto às pessoas que agora dele se beneficiam: os alunos optam por descrever verbal ou visualmente o que fizeram; e explicar sua avaliação de como o projeto os ajudou a aprender como um grupo.

Durante esse processo de avaliação, os representantes da comunidade fazem perguntas às crianças sobre suas ações e aprendizagem como feedback para promover uma maior autoreflexão e avaliação. A apresentação é colaborativa, bem como a resposta às perguntas (apesar do grande tamanho do grupo de até 25). O objetivo é que o aprendizado ocorra durante a avaliação da própria apresentação.

\section{Discussão e condições}

Provavelmente, a maior ameaça à validade das avaliações descritas acima são as condições tradicionais de aprendizagem a que as crianças participantes estão acostumadas em todas as outras áreas de sua experiência escolar. A natureza incomum das avaliações de cidadania e a preparação para elas podem ser um obstáculo ao seu aprendizado. Claramente, os promotores do programa tinham uma ideia clara sobre os tipos de aprendizagem ampla e social que este projeto iria promover e, nesse sentido, as avaliações são adequadas. No entanto, socialmente, a aprendizagem mecânica para o teste de padrões ainda é valorizada por alguns no século 21, reduzindo a validade das avaliações como consistentes com outros valores sociais.

O fato de serem avaliações baseadas em investigação, conduzidas de forma colaborativa pelos alunos, neste caso, reduzem seus benefícios de aprendizagem, a menos que sejam 
facilitados com muita habilidade - e os professores neste projeto podem não compartilhar os mesmos objetivos de aprendizagem que os promotores do programa e, portanto, não ofereça suporte adequado. $\mathrm{O}$ grande tamanho dos grupos aumenta a dificuldade dessa habilidosa facilitação.

No momento, é impossível julgar se essas questões de avaliação realmente promoveram alguma aprendizagem que valha a pena ou que valha a pena, visto que as apresentações ainda não haviam ocorrido no momento da redação deste artigo e as crianças não relataram nenhum feedback aos professores. No entanto, neste caso de avaliação colaborativa para aprendizagem, há várias razões para suspeitar que a validade pode ser diminuída, pelo menos inicialmente.

\section{Avaliação colaborativa em um mestrado universitário}

Os docentes e alunos que participaram no módulo de mestrado em avaliação da aprendizagem e da Escola de Ciências Básicas, Tecnologias e Engenharia ECBTI, e da Escola de Ciências da Saúde - ECISA, da Universidade Nacional Aberta e a Distância UNAD, resolveram converter uma soma obrigatória avaliação em um evento de aprendizagem. Todas as partes interessadas visavam promover uma aprendizagem valiosa por meio de uma avaliação colaborativa válida para a aprendizagem, apesar de serem obrigados a avaliar os alunos também de forma sumativa. A aprendizagem valiosa que pretendíamos promover incluiu a construção de conhecimentos significativos sobre avaliação para a própria aprendizagem; aprender a aprender efetivamente por meio da reflexão crítica;

Este módulo de avaliação para a aprendizagem foi o mesmo módulo mencionado acima, no qual os participantes foram convidados a priorizar os resultados da aprendizagem escolar. Seus participantes vieram de diversos países, como: Venezuela, Equador e Miami. (Onde a universidade tem um aluno e uma sede) Neste módulo, os alunos se familiarizaram com o treinamento colaborativo. desde o início do módulo. Nosso objetivo era estabelecer uma comunidade de aprendizagem nesta sala de aula, incentivando os alunos a interagir com diferentes combinações de outros alunos e a se conhecerem.

A maior parte da aprendizagem foi feita por meio de atividades em grupo ou em pares, em resposta a algum estímulo do professor. Uma aluna, XY, descreveu como essas atividades iniciais a ajudaram quando se trata de avaliação colaborativa. Ela escreveu que a avaliação colaborativa não era uma tarefa que eu tivesse empreendido antes e meus sentimentos gerais foram positivos em relação à aprendizagem em grupo, que foi derivada principalmente de outras atividades em grupo que concluímos em sessões anteriores. Cada aluno escreveu e apresentou algumas reflexões sobre a experiência do módulo, seguindo a sua conclusão: estas e outras citações semelhantes foram retiradas destes. 
Após cinco sessões semanais, convidamos cada aluno a escrever em um grande pôster ou outdoor uma breve descrição de como eles imaginaram uma avaliação válida para o aprendizado. Eles colaram seus pôsteres em uma longa folha de papel sulfite ao longo da parede e os agruparam de acordo com sua abordagem de avaliação válida para o aprendizado. Os agrupamentos formaram a base para seis grupos de redação de tarefas de avaliação. O processo de seleção não foi perfeito (um grupo teve que se dispersar e se juntar a outros), mas isso significou que a maioria das pessoas estava em grupos com interesses comuns e ninguém foi excluído por motivos sociais. Um aluno, XZ, reconheceu a dificuldade de ser forçado a colaborar na aula: Os elementos sociais do módulo eram ameaçadores e imensamente gratificantes,

Os alunos são normalmente avaliados sumativamente, na faculdade, ao escrever 5.000 palavras sobre um determinado tópico relacionado a cada módulo que frequentam. Neste módulo, nesses grupos de partes interessadas, os alunos tiveram que escrever de forma colaborativa 2.500 palavras para exemplificar uma avaliação válida para a aprendizagem e explicar o que tornava seus exemplos de avaliação válidos (e então eles escreveram um artigo individual também). Foi essa atividade que deu origem à ideia deste capítulo, e os exemplos descritos por dois dos grupos são usados como ilustrações anteriores.

O grupo teve três semanas para produzir o trabalho, que também seria postado e distribuído para outras pessoas interessadas lerem. Isso forneceria metade da base para a nota final do módulo. A comunidade concordou com os critérios de avaliação das atribuições. Durante cada sessão de aula, os seis pequenos grupos pararam suas atividades para se reunirem como uma comunidade inteira, avaliar os processos de colaboração, fornecer feedback uns aos outros e fazer planos para melhorar a colaboração. O resto do tempo, eles se concentraram em sua tarefa.

Diferentes grupos abordaram a tarefa de maneiras diferentes: alguns fizeram tudo colaborativamente até o fim; outros dividiram a tarefa e se encontraram novamente para coordenar. A maioria das pessoas usava muito o telefone e o e-mail, e alguns grupos se reuniam fora do horário escolar. Orlys Katrina, (cujas próprias avaliações em sala de aula são descritas acima) descreveu eloquentemente como o processo de redação da tarefa era de feedback constante e instantâneo, o que por si só se tornou um processo de construção colaborativa de conhecimento:

As ideias são oferecidas, os membros do grupo as avaliam em um diálogo aberto e, ao fazer isso, o proponente recebe um feedback imediato que avança seu pensamento (eles aprendem). Mais do que isso, em uma cascata de eventos de aprendizagem semelhantes, o grupo constrói novos conhecimentos. 
Outra aluna, XYZ (cujas avaliações da comunidade também são descritas acima), referiuse a um momento em que o grupo teve vontade de gritar. No entanto, ele passou a dizer que esse conflito enriqueceu seu pensamento, mas dependeu de seu bom relacionamento inicial com seus pares: Foi neste caso que o bate-papo social que tivemos antes (começando a trabalhar na tarefa de avaliação) ajudou a orientar nossa atividades. Desafiar os pensamentos dos outros acrescentou a maior riqueza ao meu aprendizado.

Durante a penúltima sessão do módulo, os seis pequenos grupos formaram três pares. Cada par trocou atribuições, de modo que todos no Grupo A leiam a atribuição do Grupo B e vice-versa. O Grupo A então discutiu a atribuição do Grupo B em relação aos tópicos. O Grupo A e o Grupo B então tiveram um diálogo de feedback sobre as atribuições um do outro em relação às questões. $\mathrm{O}$ objetivo era potencializar o aprendizado de outras pessoas, não criticar o formato da escrita.

Por esse motivo, nenhum dos grupos conseguiu alterar seu texto após o diálogo. O que eles puderam fazer foi avaliar a si próprios de forma colaborativa em relação aos critérios de avaliação como um grupo, levando em consideração o que aprenderam com o diálogo de feedback. As atribuições e autoavaliações foram entregues aos tutores e ambas foram consideradas na decisão da nota final.

O fato de a avaliação nos representar e não um indivíduo específico também foi menos ameaçador e pudemos compartilhar nosso trabalho. Essa colaboração gerou respeito e permitiu a todos os membros do corpo docente uma voz em uníssono sobre o aprendizado e sua apreciação.

\section{Discussão do módulo de mestrado}

Nesse caso, ficou claro que alguns alunos construíram novos conhecimentos sobre o assunto, avaliação para aprendizagem. Por meio da estimativa dos termos de investigação de aprendizagem, tanto durante a redação de um trabalho quanto na avaliação de outros, eles se tornaram mais conscientes de aprender sobre sua própria aprendizagem e de serem socialmente ativos e responsáveis, todos os quais eram prioridades de aprendizagem para isso módulo. Escritos subsequentes de alunos; As reflexões, assim como os trabalhos de grupo, sugeriam o mesmo, que as avaliações promoveram aprendizagens valiosas e meritórias, o que indica um bom nível de validade para essas avaliações.

Talvez aqueles alunos que já conseguiam refletir criticamente sobre sua própria aprendizagem, que já se autorregulavam e que já achavam a participação social e a comunicação mais fácil, tivessem se beneficiado mais porque estavam acostumados a maximizar sua aprendizagem por meio desses processos. No entanto, parece que as condições 
de sala de aula de qualquer maneira, propiciam a aprendizagem em todos, mas não da mesma forma.

Como o módulo era focado tanto na aprendizagem quanto na avaliação, muitos alunos pensaram sobre que tipo de aprendizagem valorizavam e compartilhavam com os objetivos de aprendizagem dos tutores, embora o modelo de avaliação fosse contra a norma universitária. Uma vez que esses objetivos eram adquirir conhecimento sobre o assunto, bem como participar como membros de uma comunidade de aprendizagem e desenvolver estratégias de aprendizagem, as avaliações foram adaptadas aos seus objetivos de aprendizagem no sentido de que eram colaborativas, mais investigativas do que orientadas. Medição (embora dentro uma estrutura de medição), e assumiram principalmente a forma de autoavaliação do grupo, embora também fossem avaliados por tutores.

Nesse contexto, o feedback foi particularmente oportuno e relevante, fornecido por colegas durante a ajuda produtiva à medida que construíam suas tarefas juntos. Esse seria mais um fator para melhorar a validade da avaliação, já que não temos dúvidas de que pelo menos alguns alunos realmente aprenderam por meio desses processos.

\section{Anotações conclusivas}

Acima estão três ilustrações de avaliações colaborativas para aprender fazendo e alguns comentários sobre a extensão de sua validade. Nosso argumento é que tais avaliações provavelmente terão um alto grau de validade se as seguintes condições forem atendidas:

- A avaliação da aprendizagem que realmente leva a uma aprendizagem posterior de um tipo que seja consistente com outros valores sociais.

- A forma e o conteúdo da avaliação de aprendizagem que reflete e promove uma aprendizagem valiosa e que vale a pena.

- A avaliação, evidenciou que se trata de um inquérito; mais do que uma medição.

- As condições da sala de aula conduzem a uma aprendizagem altamente valiosa e compensadora.

No entanto, esta lista só é útil quando avaliamos o aprendizado que nós, como sociedade, podemos priorizar. Embora possamos presumir que o currículo em nossas escolas incorpora os valores sociais predominantes, essa noção poderia ser questionada de maneira útil.

Argumenta-se neste capítulo que a aprendizagem é exclusivamente meritória se for limitada aos alunos que julgam seu significado correto em um espaço privado de conhecimento, constroem conhecimento, alertam e participam socialmente e revisam seu ensino em vários espaços; bem como reter, usar e tirar proveito das informações de forma 
conveniente. Estes são alguns dos resultados e processos de aprendizagem associados ao treinamento colaborativo e, portanto, à avaliação colaborativa válida para a aprendizagem nesse contexto.

Apesar de seus resultados desejáveis, o treinamento colaborativo e a avaliação para a aprendizagem não são comuns em salas de aula em todo o mundo. Uma longa lista de fatores atenua o risco dos professores de explorar os benefícios em suas próprias salas de aula. Talvez no topo da lista esteja a pressão percebida de avaliações sumativas impostas externamente e a competição individual, nacional e internacional que elas promovem - apesar das evidências de que as pontuações dos testes melhoram quando os alunos aprendem de forma colaborativa.

Outras razões percebidas para evitar o treinamento colaborativo e a avaliação da aprendizagem incluem a dotação de recursos; Isso apesar do fato de que o principal recurso necessário é a familiarização com processos colaborativos, porque a colaboração pode reduzir outros recursos. 


\section{Referências}

Battistich, V., Solomon, D. (1995) Schools as Communities, Poverty Level of the Student Population, and Student Attitudes, Motives, and Performance: A Multilevel Analysis, American Journal of Educational Research.

Black, P. e William, D. (1998) Inside the black box (Londres, King's College). Boud, D.

Cohen, R. e Simpson, J. (1999) Avaliação e aprendizagem entre pares, Avaliação e Avaliação no ensino superior.

Brown, A. e Campione, J. (1994) Descoberta guiada em uma comunidade estudantil em: K. McGuilly (Ed) Lições na sala de aula (Cambridge MA Press, MIR).

Campbell, P., Gray, J. e Caldwell, S. (2005) Falando e pensando juntos sobre a avaliação para aprender, em: E. Hargreaves. Exemplos de avaliação efetiva e válida para aprendizagem e explicações sobre o que a torna efetiva e válida. (Instituto de Educação, Universidade de Londres.

Crook, C. (1994) Computadores e a experiência de aprendizagem colaborativa (Londres, Routledge).

Crooks, T. (2001) A validade das avaliações formativas. Rascunho apresentado na $27^{\mathrm{a}}$ Conferência Anual de Bera, Universidade de Leeds.

Crooks, T., Kane, M. e Cohen, A. (1996) Ameaças ao uso válido de avaliações, Avaliação na Educação.

Frederikson, J. e Collins, A. (1989) Uma abordagem de sistemas para testes educacionais, pesquisador educacional. Gipps, C. (1994) Além dos testes: em direção a uma teoria da avaliação educacional.

Grupo de Reforma da Avaliação (2002) Assessment for Learning: 10 Principles.

Hargreaves, E. (2005) Avaliação para a aprendizagem? Pensando fora da caixa preta, Cambridge Journal of Education.

Jacobsen, H., McFarlane, M. e Rattan, S. (2005) Meta-aprendizagem e reflexão em avaliação para a aprendizagem, em: E. Hargreaves. Exemplos de avaliação efetiva e válida para aprendizagem e explicações sobre o que a torna efetiva e válida (Institute of Education, University of London.

Mercer, N., Dawes, L., Wegerif, R. e Sams, C. (2004) Raciocínio como um cientista: maneiras de ajudar as crianças a usar a linguagem para aprender ciências, British Educational Journal.

Messick, S. (1989) Validity, em: R. Linn. Medida Educacional American Council of Education. Nova york,

Perrenoud, P. (1998) Da avaliação formativa a uma regulação controlada dos processos de aprendizagem. Para um campo conceitual mais amplo, Avaliação em Educação.

Rosenblatt, L. (1979) The Reader, the Text, the Poem (Carbondale, IL, Southern Illinois University Press).

Serafini, F. (2001) Três paradigmas de avaliação: medição, procedimento e investigação, O professor de leitura. 
Sfard, A. (1998) Sobre duas metáforas da aprendizagem e os perigos de escolher apenas uma, Pesquisador educacional.

Stiegler, J. \& Hiebert, J. (1998) Teaching is a Cultural Activity, American Educator.

Stobart, G. (2006) A validade da avaliação formativa, em: J. Gardner (Ed) Evaluation and learning (London, Sage). Torrance, H. e Pryor, J. (1998) Investigating the

avaliação formativa (Buckingham, OUP). Watkins, C. with Carnell, E., Lodge, C., Wagner, P. e Whalley, C. (2001) Aprender sobre a aprendizagem melhora o desempenho, questões de pesquisa NSIN.

Watkins, C. (2004) Classrooms as Learning Communities, NSIN Research Matters.

Watkins, C. (2005) Classrooms as Learning Communities (London Routing).

Webb, N., Farivar, S. \& Master George, A. (2002) Productive help in cooperative groups, Theory in practice. 